\title{
A "reeducação" de Adolescentes em uma Comunidade Terapêutica: o Tratamento da Drogadição em uma Instituição Religiosa
}

\author{
Luciane Marques Raupp \\ Universidade de São Paulo \\ Clary Milnitisky-Sapiro \\ University of California - Berkeley e Universidade Federal do Rio Grande do Su
}

\begin{abstract}
RESUMO - O abuso de drogas por adolescentes é, atualmente, um grave problema de saúde pública. Nessa área, a questão do tratamento destaca-se como um grande desafio, principalmente pelo fato de a maioria das intervenções não estar adaptada às especificidades desse público. Neste trabalho, serão apresentados os resultados de uma investigação que visou analisar o tratamento destinado a adolescentes em uma modalidade de atenção distinta das abordagens tradicionais da área da saúde: a comunidade terapêutica. Buscou-se compreender as concepções e práticas de atenção da instituição pesquisada, comparando-as com o prescrito pelas políticas públicas do setor. Os métodos utilizados foram a descrição etnográfica e a análise de conteúdo. Os resultados sugerem uma defasagem entre o prescrito pelas políticas públicas e a realidade da comunidade terapêutica pesquisada, a qual, apesar de proporcionar acolhimento às adolescentes, dificulta o desenvolvimento de suas singularidades e potencialidades devido à ênfase no "modelo moral" de tratamento da drogadição.
\end{abstract}

Palavras-chave: dependência de substâncias psicoativas; adolescência; comunidades terapêuticas.

\section{The Re-education of Adolescents in a Therapeutic Community: The Drug Addiction Treatment in a Religious Institution}

\begin{abstract}
Drugs abuse by adolescents is, nowadays, a major problem of public health. In this field, treatment represents a great challenge, mainly due to the fact that most interventions are not adapted to the adolescents' specificities. The present paper shows the results of an investigation which aimed to analyze the treatment of adolescents through a mode of care that is different from the traditional practices in public health: the therapeutic community. This research tried to understand the conceptions and practices regarding care in the researched institution, comparing them to what is stated by health-related public policies. The research methods utilized were ethnographic description and content analysis. Results suggest that there is a gap between what is stated by public policies and the reality of the therapeutic community that was researched, which, albeit providing shelter and care for the adolescents, make the process of development of their singularities and potentialities difficult, due to its emphasis on the "moral model" of drug addiction treatment.
\end{abstract}

Key words: dependence of psychoactive drugs; adolescence; therapeutic community.

As questões relativas ao abuso de álcool e outras drogas são consideradas, atualmente, um grave problema de saúde pública. Nessa área, o tratamento de adolescentes destaca-se como um dos grandes desafios, dada a alta prevalência de uso, que vem ocorrendo cada vez mais precocemente (Guimarães, Godinho, Cruz, Kappann, \& Tosta Junior, 2004; Prata \& Santos, 2007; Toscano, 2001), associado a altos índices de abandono e baixo sucesso terapêutico (Kaminer \& Szobot, 2004).

Considera-se que tais dificuldades relacionam-se ao fato de o consumo e a circulação de drogas envolverem, na atualidade, uma multiplicidade de questões inter-relacionadas, em diferentes níveis de complexidade. Segundo Birman (1999), essas relações se inscrevem nos registros teórico, clínico, social, político e ético e constituem temas de investigação relacionados a diferentes saberes, ligados pela busca de compreensão das ambigüidades da sociedade contemporânea em relação às drogas.

Quando o uso de drogas ocorre na adolescência, é imprescindível reconhecer as várias operações psíquicas que se dão nessa fase e que irão conferir características e necessidades peculiares a esse grupo. Nesse sentido, qualquer programa de tratamento que se destine a adolescentes necessita criar dispositivos sensíveis e capazes de acolhê-los e auxiliá-los a enfrentar os desafios inerentes a esse período de indecisão subjetiva e de incerteza social (Rassial, 1997). Além disso, do ponto de vista clínico, é imprescindível a existência de um plano terapêutico individual que leve em conta a história e a biografia do sujeito (ANVISA, 2001), assim como a contribuição de cada fator de risco de uma maneira individualizada, porque não há causas que possam ser tomadas de maneira universal (Simões, 2006). Também a família deve ser considerada como parte essencial do tratamento, pois os problemas relacionados a ela tendem a encontrar, freqüentemente, expressão no adolescente (Dualib, 2006; Simões, 2006).

Evidenciando a importância de problematizar os modelos de tratamento utilizados atualmente para lidar com essas questões, abordaremos neste presente trabalho uma modalidade de atenção muito difundida, embora ainda pouco estudada: a comunidade terapêutica (CT). Essa modalidade de atenção, surgida na Grã-Bretanha na década de 1940, foi inicialmente utilizada para a atenção a pacientes psiquiátricos 
crônicos e só posteriormente adaptada ao tratamento da drogadição. Atualmente, existe como uma opção de tratamento que se desenvolve à margem das correntes terapêuticas tradicionais, embora seja largamente utilizada, principalmente no caso de sujeitos dependentes de drogas e desprovidos do suporte social necessário para obter êxito em uma modalidade menos intensiva de atenção (De Leon, 2003).

Há ainda muito desconhecimento e preconceito em relação às CTs, principalmente entre os profissionais da área da saúde, os quais tendem a encaminhar pessoas para esses locais apenas "como último recurso", geralmente por não encontrarem vagas em outras instituições. No entanto, principalmente pela escassez de locais de tratamento, as CTs difundem-se cada vez mais, geralmente por iniciativa de ex-usuários de drogas, os quais fundam novas comunidades, segundo o modelo daquelas nas quais obtiveram recuperação, geralmente sem contar com os recursos e a formação necessários para adequar seu funcionamento aos requisitos exigidos por lei.

Segundo dados oficiais (Federação Brasileira das Comunidades Terapêuticas, 2006), o Brasil conta com 80 comunidades filiadas. Contudo, sabe-se que esses dados não refletem a realidade numérica dessas instituições, pois existem ainda várias $\mathrm{CTs}$ em funcionamento que não são filiadas a essa federação e não encontram-se adequadas, estrutural e/ou funcionalmente, às normas mínimas exigidas para o funcionamento desses locais, segundo a Resolução no 101 da Agência Nacional de Vigilância Sanitária em parceria com a Secretaria Nacional sobre Drogas (ANVISA, 2001), que submete esses locais aos conselhos de entorpecentes municipais, estaduais, federal e à vigilância sanitária (Sabino \& Cazenave, 2005).

Segundo Serrat (2002), a expansão das CTs no Brasil é uma resposta à evolução do consumo de drogas, associado à escassez de políticas públicas consistentes e abrangentes. De acordo com esse autor, quando os princípios de recuperação, resgate da cidadania, reabilitação física e psicológica e de reinserção social são corretamente aplicados, os tratamentos em comunidades apresentam resultados positivos importantes, agindo principalmente nos fatores psicossociais associados à dependência.

\section{Método}

Os resultados apresentados a seguir são oriundos de uma pesquisa de mestrado que teve por objetivo descrever e analisar diferentes modalidades de atenção a adolescentes usuários de drogas, visando compreender as principais diretrizes e práticas de tratamento de três instituições pertencentes à rede pública de Porto Alegre que oferecem tratamento para a drogadição e recebem adolescentes (Raupp, 2006). Os locais pesquisados foram: um ambulatório; uma unidade especializada de um hospital geral; e uma CT, que foram selecionados com indicações do Conselho Municipal de Entorpecentes. No presente estudo, serão abordados exclusivamente os dados e análises relativos à CT. Escolheu-se enfocá-la por representar uma forma de atenção diferenciada e pouco estudada, fazendo-se, portanto, necessário difundir conhecimentos e incentivar a produção de pesquisas sobre o tema.

Para a coleta e análise dos dados, empregou-se um método qualitativo, de caráter descritivo, envolvendo dois níveis de investigação, em duas etapas distintas.
$\mathrm{Na}$ primeira etapa, buscou-se descrever o contexto das instituições selecionadas pelo emprego da descrição de cunho etnográfico (Loss \& Milnitsky-Sapiro, 2005; Menegaz \& Milnitsky-Sapiro, 2002; Milnitsky-Sapiro, 2001; Raupp \& Milnitsky-Sapiro, 2005). Na descrição de cunho etnográfico, faz-se uso de uma triangulação entre o material proveniente das observações efetuadas (registradas em um diário de campo); os documentos disponíveis para consulta (prontuários, estatutos e material de divulgação); e entrevistas. A adoção dessa fase possibilitou um conhecimento aprofundado de cada instituição a partir da observação de seu cotidiano e funcionamento; da consulta a registros históricos e documentais; e do acesso à opinião dos entrevistados por meio de conversas informais e da realização de entrevistas semi-estruturadas, com questões abertas, visando conhecer a trajetória de cada entrevistado, sua opinião sobre o serviço e sugestões para sua melhoria.

Foram entrevistados dois profissionais e três adolescentes em cada local, a partir dos critérios de disposição em participar da pesquisa, voluntariedade, anonimato, tempo mínimo de um mês de tratamento (para os adolescentes) e assinatura de Termo de Consentimento Esclarecido e Informado. Os entrevistados na CT foram: Maria, 28 anos, freira, coordenadora da instituição; Paulo, 36 anos, administrador de empresas e estudante de psicologia, atua como voluntário na CT; Bruna, 16 anos, em tratamento há um mês; Amanda, 15 anos, em tratamento há cinco meses; e Carol, 18 anos, em tratamento há cinco meses.

O emprego desse método permitiu às pesquisadoras uma "imersão" no local de pesquisa, facilitando-lhes compreender como se produzem as práticas institucionais. A equipe acolheu bem as pesquisadoras, permitindo-as observar todas as atividades coletivas, tais como laborterapia, oficinas, grupos de auto-ajuda, e até mesmo compartilhar refeições com as internas, desde que fosse previamente avisado quanto aos dias e turnos de observação, que ocorria três vezes por semana, em dias e turnos alternados, durante um mês. Nesses momentos, as pesquisadoras permaneciam próximas às residentes, observando as tarefas que executavam e conversando com elas ou, por vezes, apenas observando os fatos e diálogos para, posteriormente, transcrevê-los no diário de campo. No transcorrer do trabalho, as adolescentes foram, gradualmente, manifestando familiaridade com as pesquisadoras, muitas vezes procurando-as para conversar e compartilhar sentimentos ou até mesmo para contar pequenas transgressões que realizavam ou manifestar sua vontade de desistir ou prosseguir no tratamento. Nesse sentido, concorda-se com Dalmolin, Lopes e Vasconcelos (2002) quanto ao emprego do método de cunho etnográfico aproximar o pesquisador da dinâmica do grupo social estudado, auxiliando na compreensão do sentido dessas experiências e das estratégias das quais lançam mão no cotidiano.

$\mathrm{Na}$ segunda etapa, os dados coletados foram analisados pela utilização do método de análise de conteúdo (Bardin, 1977). Durante esse procedimento, foram identificados temas emergentes do trabalho de campo e das entrevistas realizadas, os quais delinearam a constituição de categorias e suas subseqüentes interpretações. Para tanto, contou-se com a participação de duas auxiliares de pesquisa.

A seguir serão expostas as principais categorias emergentes da análise dos dados coletados. Inicialmente será descrito o contexto da CT, considerando sua estrutura, rotina 
e práticas, conforme observado no trabalho de campo e nas consultas documentais e conversas informais realizadas. Após, serão apresentadas as categorias emergentes das entrevistas efetuadas, as quais explicitam as práticas e concepções que regem o tratamento, assim como a opinião das adolescentes sobre ele.

\section{Resultados}

\section{Descrição do contexto}

A comunidade pesquisada diferenciava-se de grande parte das CTs por ser uma instituição "urbana", localizada nos arredores da cidade de Porto Alegre (diferentemente da maioria das "fazendas terapêuticas" localizadas na área rural) e "feminina", pois recebia apenas jovens do sexo feminino de 12 a 21 anos . Foi fundada na década de 1990 pela Cúria Metropolitana e, a partir de então, administrada por uma congregação de religiosas. No momento da pesquisa, ocupava as instalações de uma antiga escola. Era administrada por uma freira e incluía outras três religiosas responsáveis pela organização das rotinas, disciplina e coordenação de grupos de auto-ajuda, as quais possuíam instrução de nível médio e não possuíam cursos na área. O local contava também com a presença de diversos voluntários ministrando oficinas de trabalhos manuais (tricô e bordado), música, informática, recreação, jardinagem, grupos de auto-ajuda (Amor-Exigente e Grupo de Doze Passos dos Alcoólicos Anônimos), atendimento médico-psiquiátrico e ginecológico. Cabe ressaltar que, diferentemente dos outros voluntários, os médicos compareciam na CT para realizar consultas previamente agendadas e nenhum deles era responsável pelo programa terapêutico, conforme exige a Resolução 101 (ANVISA, 2001) , este ficava sob a responsabilidade da coordenadora do local. A rotina diária de atividades baseava-se em um cronograma fixo de atividades, que deveriam ser rigidamente cumpridas, sob supervisão, e dividiam-se entre: laborterapia (atividades diárias de limpeza e organização da comunidade); atividades religiosas; e oficinas ministradas por voluntários. A Tabela 1, ilustra a rotina de dois dias na CT estudada, organizada segundo as atividades previstas para cada horário do dia.

O local possuía também a peculiaridade de não ter monitores em seu quadro fixo. Contudo, a equipe contava com o auxílio operacional de residentes que, após completarem seu tratamento, seguiam por mais três meses na CT fazendo um estágio de monitoria.

O tratamento nessa modalidade de atenção ocorria em regime residencial. O ingresso deveria ser voluntário, com aceitação por escrito de suas normas e seu regulamento. O programa durava nove meses, podendo ser prorrogado por até um ano, de acordo com a avaliação da equipe sobre a evolução de cada adolescente. A permanência no local deveria ser custeada pelas famílias, mediante contribuições mensais de acordo com a renda, ou pelo órgão público responsável pelo encaminhamento.

\section{Concepções sobre as adolescentes}

Nessa categoria, busca-se explicitar as concepções dos profissionais entrevistados acerca das adolescentes e suas principais necessidades. Segundo a coordenadora, quando as residentes se deparam com a obrigação de cumprir o cronograma da CT, manifestam grandes dificuldades no desempenho de tarefas básicas, tais como higiene pessoal ou organização da casa, por isso considera que as mesmas não sabem fazer nada e, por isso, necessitam de limites e reeducação:

Todas as adolescentes que são encaminhadas pra casa têm um comportamento anterior que já era uma droga. Elas não sabem fazer nada, só aquilo que é errado.

Então o que nós precisamos, é ter coragem para impor limites a elas, com toda caridade e entendendo o lado dessas adolescentes, por que são todas meninas que tiveram marcas em sua infância de rejeição, espancamento, violência, e que hoje precisam ser amadas, corrigidas e ensinadas, por que não sabem nada, só aquilo que é errado, com firmeza e colocando limites.

Para Paulo, o voluntário entrevistado, esse comportamento marcado por "saber só o que é errado" estaria ligado à ausência de apoio familiar. Sem essa base, as adolescentes sentir-se-iam perdidas e sem referências:

Das que eu conheci lá, em geral, têm um percurso com droga escondido da família, vai pra roubo, prostituição (...). Muitas com estrutura familiar ruim, moram com o tio, com qualquer um, e vão passando de casa em casa. Então, a maioria delas, é esse o percurso, essa coisa perdida, sem apoio, sem estrutura familiar.

Tabela 1. Cronograma de atividades de três dias da semana na comunidade terapêutica.

\begin{tabular}{llll}
\hline Hora & Dia 1 & Dia 2 & Dia 3 \\
\hline 06:30 & Despertar & Despertar & Despertar \\
07:30 & Espiritualidade & Espiritualidade & Espiritualidade \\
08:00 & Catequese & Reunião de 12 Passos & Reunião de 12 Passos \\
09:00 & Laborterapia & Laborterapia & Missa \\
10:00 & Laborterapia & Laborterapia & Laborterapia \\
12:00 & Almoço & Almoço & Almoço \\
13:00 & Laborterapia & Laborterapia & Laborterapia \\
14:00 & Atividades Lúdicas & Aulas de Violão e Jardinagem & Aula de crochê e bordado \\
16:00 & Lanche & Lanche & Lanche \\
16:30 & Banhos & Banhos & Banhos \\
18:00 & Jantar & Jantar & Jantar \\
19:00 & Livre/Leitura & Grupo de Oração & Partilha Comunitária \\
20:00 & Reunião de Amor Exigente & Grupo de Jovens Cristãos & Partilha Comunitária \\
\hline
\end{tabular}




\section{A reeducação}

Nos próximos relatos, Maria expõe os princípios que regem o tratamento, as atividades que compõem o programa terapêutico da CT e seu principal objetivo: a reeducação das adolescentes:

Nosso critério é: espiritualidade, trabalho e disciplina (...). Todo o programa da casa é importante: a realização dos doze passos, os grupos, os princípios de Amor Exigente, a Laborterapia; todos os trabalhos que se passam na casa são terapêuticos, visando à recuperação e a reeducação dela.

O objetivo é trabalhar na reeducação das adolescentes, corrigir aquilo que elas faziam de maneira errada na rua, moldando-as através do programa terapêutico.

\section{O tratamento de adolescentes}

Segundo o relato de Maria, o adolescente seria mais receptivo ao tratamento do que o adulto, pois, enquanto este acha que já sabe tudo, o adolescente, ao mesmo tempo em que questiona e enfrenta a equipe, mostra-se mais disposto a aprender. Destaca também a paciência e perseverança necessárias para lidar com esse público:

Eu acho que, por mais difícil que seja trabalhar com adolescentes, eles têm uma aceitação, não é todos, mas o adulto, ele acha que já viveu demais, que ele sabe tudo e que uma CT não tem nada a acrescentar a ele (...). O adolescente, desde uma atividade na cozinha que a irmã vai ensinar a elas, elas ficam atrapalhadas, mas ela está disponível a aprender, resmunga, briga, questiona, tem que ter muita paciência e pedagogia pra trabalhar com eles, que não adianta gritar, mas corrigir com firmeza e, com o passar do tempo, vemos que elas vão adquirindo, não é nos primeiros dias, mas com o tempo vão tomando consciência e fazendo parte do programa.

No próximo relato, o voluntário entrevistado afirma que $\mathrm{o}$ tratamento deveria priorizar a atenção individual às adolescentes, ao invés de apenas o trabalho coletivo, possibilitando o trabalho com suas singularidades:

Eu acho que o apoio individual é muito importante, por que elas, realmente, elas não têm. As irmãs não têm formação pra isso, além da droga, elas têm muitos problemas pessoais, então a droga talvez seja tratada lá, os problemas pessoais, tudo de uma forma muito coletiva. Então, o que eu vejo é uma grande carência delas de alguém ouvi-las, de acolher, de alguma coisa assim. Então, eu acho que o individual seria o mais importante.

\section{Convivendo noves meses em comunidade}

Nessa categoria, destacamos relatos das adolescentes entrevistadas, nos quais expressam suas dificuldades de adaptação à vida na CT. No trecho abaixo, Amanda destaca as dificuldades da convivência grupal:

Minha experiência aqui foi assim: quando eu cheguei me trataram muito bem, só que tinha conflitos, muitas coisas que eu não consegui mudar ainda e pretendo mudar: conflitos, brigas, fofocas, bate-boca por causa de uma coisa simples, que é fácil de resolver.

No próximo relato, Bruna desabafa sobre suas dificuldades, principalmente relacionadas a ter de se conhecer pela opinião da equipe e das colegas e, assim como no relato de Carol, a seguir, refere os esforços de conscientização e amadurecimento requeridos pela recuperação e suas dificuldades:

Não é só que eu quero, eu preciso ficar. Eu vou ter que ficar, né, vou ter que fazer por mim, e dá medo, por que isso aqui é horrível, sabe, se conhecer, ver os outros te julgando, falando teus defeitos, bá, é muito ruim, muito ruim... pensamento ruim o tempo inteiro, por mais que tu tente fazer o bem, as coisas ruins te perseguindo.

Aqui na comunidade é muito confuso, sabe, há dias, assim, que eu to muito bem e que eu olho, vejo alguma irmã me exigindo alguma coisa, alguma semelhante, companheira aqui da casa, me ajudando, me orientando, eu acolho de uma forma tão boa, sabe. Mas quando me deparo com aqueles defeitos que eu vejo que eu tenho desde criança, aí é mais confuso pra mim.

No relato abaixo, Bruna descreve a rotina da casa e as dificuldades do dia a dia, principalmente relacionadas à grande quota de paciência e resignação exigidas. Diante das dificuldades expressas, considera o tempo total do tratamento insuficiente, dada a imensa tarefa de mudar radicalmente:

Nove meses eu acho pouco ainda, pra uma pessoa nascer de novo, como elas falam, ainda nove meses é pouco, mas, sabe, é apavorante nove meses. $E$ tu, tem que ser tu e tu aqui dentro, tem que fazer as coisas que os outros fazem, e limpa, não importa, vai lá e faz de novo, faz melhor do que fez na primeira vez, se elas voltarem a sujar, não importa, vai lá e limpa de novo que é serviço teu, que tá na tua escala. Eu faço, tô trabalhando um monte nisso essa semana, tô tentando, minhas orações também, eu preciso que me fortaleçam pra eu melhorar.

\section{Avaliação do tratamento}

Todas as adolescentes referiram que, apesar das dificuldades de relacionamento e dos conflitos existentes, sentiam-se "acolhidas", "ensinadas", "ajudadas" e "compreendidas"; avaliando positivamente a instituição e, inclusive, considerando que a equipe deveria ser ainda mais exigente como demonstram, respectivamente, os relatos de Amanda, Carol e Bruna:

A experiência aqui é muito boa, por que as pessoas me ajudam e me entendem e eu ajudo as pessoas também a se conhecerem mais. Te traz uma paz, uma tranqüilidade.

Há, se eu for falar o que eu gostaria pra mim, seria muito cômodo, por que eu acho que aqui tem tudo o que tinha que ter numa comunidade terapêutica: exigência, carinho-porque as irmãs dão bastante carinho.

Eu acho que precisava ser mais rígido. A gente tem que aprender o que é correto. Eu acho que nove meses é pouco ainda pra uma pessoa nascer de novo, mas, sabe, é apavorante nove meses. 


\section{Discussão dos Resultados}

A descrição etnográfica realizada na $\mathrm{CT}$ proporcionou às pesquisadoras uma "imersão" no seu cotidiano, que foi fundamental para a compreensão de uma instituição tão diferenciada. O tempo prolongado de internação, o estatuto de residente dado às adolescentes, a ausência de técnicos fixos e a influência religiosa - a qual fazia-se presente em todo o seu ambiente, por exemplo, em sua estrutura física (capela, imagens religiosas), atividades (orações pela manhã, antes das refeições e à noite, catequese, crisma, missas etc.) e regras - são exemplos da peculiaridade dessa modalidade

Conforme demonstraram as entrevistas realizadas, o objetivo principal do tratamento na CT não se restringia ao alcance da abstinência de drogas, mas visava algo que a continha e ultrapassava, denominado pela coordenadora da instituição como a reeducação e a transformação das adolescentes. Para o alcance desses fins, os principais instrumentos terapêuticos da instituição (espiritualidade cristã, trabalho e disciplina) eram utilizados como meios para viabilizar esse processo, ao transmitir valores, estabelecer limites e "moldar" as residentes. Isso pode ser constatado na ênfase dada à laborterapia no programa terapêutico, ou seja, o uso do trabalho como forma de tratamento e de exercício da disciplina, demonstrada pelo grande espaço de tempo reservado a essa atividade no cronograma da CT, o que, por outro lado, também pode estar ligado à ausência de profissionais especializados responsáveis pelo programa terapêutico. Quanto a esse ponto, cabe destacar que, no momento da pesquisa, apenas duas residentes recebiam atendimento psicoterápico semanal (pelo psiquiatra voluntário) e uma "terapia de apoio" era eventualmente executada pelas freiras. A maior parte dos momentos de fala e reflexão sobre a recuperação e suas dificuldades ocorria durante os grupos de auto-ajuda.

Ainda no que se refere à laborterapia, essa é considerada o ponto central do programa terapêutico de qualquer CT, o qual, segundo uma das portarias que regulamenta o funcionamento dessas instituições, deve estar estruturado “(...) a partir da prática de cuidados cotidianos, que contemplem experiências de reorganização do tempo e do espaço, respeitando as demandas singulares de cada sujeito" (Governo do Estado do Rio Grande do Sul, 2001, p. 18). No entanto, diferentemente disso, na CT a escala semanal não estava estruturada de forma a adequar-se às demandas das residentes, era fixa e obrigatória. A residente que não a cumprisse adequadamente estaria sujeita à aplicação de "medidas educativas", uma espécie de punição por mau-comportamento, geralmente implicando a execução de serviços extra de limpeza.

Além da laborterapia, outro aspecto fundamental do tratamento da drogadição em uma CT liga-se à importância conferida à vivência comunitária e aos desafios que ela suscita, conforme demonstraram as adolescentes na categoria Convivendo nove meses em comunidade. Segundo a Resolução no 101, "o principal instrumento terapêutico de uma CT é a convivência entre os pares que compartilham de uma mesma problemática" (ANVISA, 2001), enfatizando os efeitos socializantes e terapêuticos da convivência grupal. Durante o período de observação das rotinas da CT, percebeuse uma alternância entre momentos de integração, harmonia e apoio mútuo entre as residentes, e inúmeras ocasiões de conflitos, brigas e intrigas, demonstrando o caráter prazeroso e, ao mesmo tempo, difícil e desafiante da convivência grupal. Nesse contexto, a atuação da equipe era fundamental na administração dos conflitos emergentes, visando trabalhar atitudes identificadas como individualistas ou prejudiciais ao tratamento.

Sublinhando o caráter terapêutico da convivência grupal, Conte (2003) refere que o tratamento em uma CT tem o objetivo de possibilitar que o residente exercite um tipo de sociabilidade no qual não ocorra o uso de drogas. Espera-se que eles possam retomar seu interesse por atividades e relações sociais que haviam sido abandonadas e assumir novas formas de interação social.

Além da laborterapia e da convivência comunitária, outros dois pontos fundamentais que devem constar no programa terapêutico de uma CT (segundo as normas que regulamentam o setor e a literatura especializada) e que não estavam presentes no local pesquisado são: a visita periódica a espaços culturais da cidade e o desenvolvimento de atividades profissionalizantes. Diferentemente do estabelecido, no local estudado, as residentes só saíam da comunidade em casos excepcionais (tais como doença ou compromissos judiciais) ou a partir do sexto mês de tratamento, quando passa a ocorrer a "visita terapêutica", momento no qual a adolescente passa uma semana por mês em sua casa, visando sua readaptação à família e comunidade. Quanto à profissionalização, eram oferecidas aulas de computação, oficinas de violão, crochê e bordado, no entanto, à exceção das aulas de computação, considera-se que as demais se enquadram melhor no âmbito de atividades lúdico-terapêuticas, ao invés de profissionalizantes.

Encontramos, em diversas passagens das entrevistas realizadas na CT, relatos que relacionavam as principais necessidades das adolescentes à busca por acolhimento, limites, atenção, escuta, compreensão, que não havia sido suprida satisfatoriamente em suas relações familiares e educativas, conforme expresso pelos profissionais entrevistados na categoria concepções sobre as adolescentes. Indicando que a instituição está de alguma forma suprindo essas necessidades, todas as adolescentes entrevistadas referiam que, apesar da rigidez e das exigências, sentiam-se ajudadas, ensinadas e compreendidas, avaliando positivamente a instituição e, inclusive, considerando que a equipe deveria ser mais rígida. Buscando subsídios para compreender esse posicionamento, encontramos entre autores vinculados à análise psicanalítica do processo adolescente algumas indicações.

Para autores como Rassial (1997) e Melman (1995), é necessário compreender a fase adolescente como uma operação de passagem e uma "crise psíquica" fundamentais para o processo de desenvolvimento humano, na qual a busca por referências ocupa um lugar fundamental. Segundo Rassial (1997), as principais manifestações e necessidades desse período relacionam-se à indecisão subjetiva e à incerteza social, as quais o constituem e o caracterizam como uma "posição no intervalo" (p. 35), convocando à busca por novos lugares e possibilidades identificatórias. Além disso, Levisky (1997) sublinha a disposição dos adolescentes a "passar ao ato" (p. 18), referindo-se à tendência a descarregar seus impulsos agressivos e sexuais diretamente, pelo processo primário, em busca da satisfação imediata dos seus desejos. Para o autor, nesse processo, freqüentemente, os jovens pensam apenas depois de 
realizar a ação, muitas vezes percebendo as consequiências de seus atos somente depois de os terem realizado.

Considerando que esse processo se dá, atualmente, em um contexto social caracterizado pela "liquefação de valores", individualismo e instantaneidade (Bauman, 2001, 2005), compreenderemos o sentimento de estarem "perdidas" e "vazias", tantas vezes manifesto pelas adolescentes. Nesse contexto em que as referências se multiplicam, sem parâmetros, os jovens podem ser levados "de forma ainda mais confusa no sem-fundo da desterritorialização contemporânea em um momento em que eles próprios habitam um sem-lugar" (Oliveira, 2001, p. 82). Devido ao acúmulo dessas influências, agravado pela situação de desamparo produzida pela institucionalização e afastamento da família, talvez se possa explicar a importância que adquire ser cuidado, protegido e contido em um ambiente com características "familiares", no qual, para muitas adolescentes, pela primeira vez há pessoas interessadas em seu desenvolvimento pessoal. Levisky (2005) sublinha que quando um ambiente oferece condições de continência, de holding, pode facilitar que as pulsões do adolescente - geralmente tensas e turbulentas - sejam processadas e reconfiguradas dentro de enquadramentos melhor definidos, nos quais possam ter maiores possibilidades de encontrar seus sistemas internos de equilíbrio e interação social.

Além disso, referindo-se à realidade dos que são entregues precocemente às instituições de proteção, vivem em situação de rua ou mesmo as crianças que, "sendo mais uma - uma a mais - dentre muitas a dividir um pequeno espaço" (p. 42), carecem de possibilidades mínimas de subjetivação, Cruz (2003) afirma a necessidade imperiosa de construir recursos que permitam alguma condição subjetiva de existência a esses indivíduos. Diante da comum ausência de possibilidades, esses jovens freqüentemente estabelecem relações que têm por base a "sexualização" precoce de seus corpos, a transgressão, a delinqüência ou, ainda, a busca da anestesia e apagamento pela intoxicação. Na ausência de respostas sociais eficazes a essas questões, o autor aponta a religião como o que, ainda hoje, mais se aproxima da oferta de uma resposta ao associar a drogadição ao "distanciamento de Deus" e, portanto, oferecendo como solução o restabelecimento dessa ligação. Além disso, a inserção em uma religião, proporcionada pelo tratamento na $\mathrm{CT}$, vincula os adolescentes a uma nova comunidade, na qual encontram lugares onde se inserir e respostas para suas perguntas, o que, muitas vezes, pode atuar como uma necessária âncora para subjetividades errantes.

Considerando as características acima referidas, as quais compõem a modalidade de tratamento da CT pesquisada, conclui-se que seu programa terapêutico corresponde ao postulado por Marlatt e Gordon (1993) como o modelo moral de tratamento. Segundo esses autores, este modelo constitui o viés mais tradicional no campo do tratamento ao abuso e dependência de drogas. Nessa visão, embasada na moralidade cristã, o uso excessivo de qualquer substância é visto como um problema de controle do impulso, no qual falta ao indivíduo força de vontade para exercer controle sobre si. Dessa forma, alguém que abuse ou seja dependente de alguma substância é compreendido como uma pessoa a quem falta "fibra moral" para resistir à tentação.

Compreende-se que a CT estudada correspondia a esse modelo, principalmente por ter na doutrina cristã sua prin- cipal referência. Além disso, sua rotina de atividades estava estruturada de forma a controlar os impulsos das adolescentes e "moldar" seu comportamento segundo os parâmetros morais da doutrina cristã, trabalhando de forma intensiva suas capacidades de postergar, substituir e reprimir seus impulsos. Toda a orientação educativa do programa terapêutico atuava sob esses dois aspectos centrais: a disciplina e a reeducação, visando o "renascimento" do sujeito em outra ordem moral.

Outro aspecto do modelo moral encontrado na instituição ligava-se à premissa, presente no discurso da equipe, segundo a qual os indivíduos são considerados responsáveis pelo "início, desenvolvimento e solução dos seus problemas, necessitando apenas de motivação apropriada para isso" (Marlatt \& Gordon, 1993, p. 13). Pode-se encontrar um exemplo dessa visão em uma citação do material de divulgação da CT, no qual é enfatizado o esforço e o trabalho pessoal necessários à recuperação, colocando a mesma como um desafio a ser conquistado dia após dia na comunidade, baseado no trabalho fraternal e no esforço constante para o alcance de uma vida melhor.

Nesse sentido, a recuperação era vista como a resultante de esforços pessoais para adequar-se ao funcionamento do programa e suas premissas, o que, na prática da instituição, não deixava espaço para o reconhecimento de fatores inconscientes, sociais ou contextuais associados à função ocupada pelo uso de drogas na vida das adolescentes. Dessa forma, o tratamento na CT tendia a desconsiderar a singularidade das histórias de vida de suas residentes ao propor sua conversão a uma moral específica e a adaptação de seus comportamentos ao que é considerado "correto" nessa doutrina. Consideravase que o auxílio do grupo de pares, o cumprimento estrito das regras e dos Doze Passos e, principalmente, a entrega verdadeira a Deus e a seus mandamentos seriam os únicos requisitos para a recuperação das adolescentes.

Pillon e Luíz (2004) enfatizam o efeito de culpabilização presente nessa abordagem. Segundo os autores, o modelo moral levaria as pessoas a sentirem-se culpadas por sua drogadição e a pensarem que, de alguma forma, lhes falta força de vontade ou "fibra moral" para alterar sua situação.

\section{Conclusão}

Com base na análise efetuada, concluiu-se que, apesar de a CT pesquisada proporcionar continência, segurança e acolhimento às adolescentes, ajudando-as a restabelecer relações de confiança e reestruturação egóica, o modelo moral que embasava o tratamento dificultava o desenvolvimento de suas singularidades e potencialidades e, conseqüentemente, o alcance de uma recuperação duradoura.

Constatou-se também que o programa terapêutico da instituição não estabelecia distinções entre uso, abuso e dependência de álcool e outras drogas, aplicando exatamente o mesmo tratamento a todas as residentes, independente de seu grau de envolvimento, substância utilizada ou idiossincrasias. Paralelamente a essa indistinção, e agravando o problema por ela representado, o tratamento não previa espaços terapêuticos individuais, dispositivos fundamentais para a construção de um entendimento aprofundado das relações do sujeito com o uso de drogas como um sintoma de sua problemática psíquica.

No que concerne à imposição da moral cristã como o cerne do tratamento, responsável pela "fervorosa" conversão de 
algumas residentes ao catolicismo, concluiu-se que, na maioria das vezes, a mesma se configurava como uma doutrinação, e não como uma resposta adequada às suas necessidades, dado que a maioria delas, ao sair dali, não teria desenvolvido os recursos necessários para fazer outras opções de vida, a não ser voltar para suas condições anteriores, ser freira ou monitora de CT.

Por isso, considera-se que o estilo de vida incentivado pelo programa da CT pesquisada fornece modelos de identificação rígidos demais para as características do mundo atual, não instrumentando as adolescentes para a construção de opções de vida viáveis. Explicitando esse processo, Bauman (2005) afirma que vivemos em uma época na qual o mundo está repartido em fragmentos mal coordenados e fragilmente conectados, no qual predominam a velocidade e as mudanças. Devido a isso, nos acostumamos a manter nossas referências identitárias em constante movimento, absorvendo-as e descartando-as com muita rapidez. Nesse contexto, as antigas estruturas de referência, demasiado "sólidas" e duráveis, às quais dificilmente se agregam novos conteúdos, são de pouca utilidade, simplesmente não funcionam. Por outro lado, tanta velocidade é potencialmente geradora de grande ansiedade, estimulando o desejo pela segurança proporcionada pela adesão a uma identidade definida. Contudo, a adesão a uma identidade rígida e fixa demais, dentro da infinidade de possibilidades atuais, também não é uma perspectiva atraente, a qual dificilmente fornecerá a estruturação necessária para a vida em um mundo em constante transformação.

Referindo-se aos tratamentos oferecidos nas CTs, Rotelli (1990) afirma que esses já foram locais de promoção da subjetividade das pessoas, em que as dimensões individuais eram recuperadas por meio das relações de troca no interior dos grupos, nos quais as experiências eram valorizadas e enriquecidas. A observação na CT pesquisada demonstrou o potencial dessa modalidade para a atenção a adolescentes desprovidos de recursos sociais e familiares mínimos, capazes de proporcionar o acompanhamento e acolhimento necessário para auxiliar a modificação de relações de exclusividade e autodestruição estabelecidas com as drogas em uma modalidade de atenção menos restritiva. No entanto, devido às limitações encontradas no local pesquisado, concorda-se com Rotelli (1990), no tocante à tendência de transformação desses locais em espaços de "ortopedia” (p. 73), onde não há possibilidade de reconhecimento e valorização das singularidades, pois todos devem adequar-se às verdades pré-estabelecidas, padronizando as possibilidades de desenvolvimento.

Acreditando na possibilidade de transformação dessa realidade, recomenda-se que as CTs recebam maior atenção e investimentos, pois vêm ocupando um lugar importante nesse campo, no qual impera a ineficácia do poder público. Se as orientações das políticas públicas que regulamentam o funcionamento desses locais fossem efetivamente adotadas e fiscalizadas, especialmente a regulamentação da ANVISA (2001), poder-se-ia qualificar as CTs, principalmente pela capacitação dos membros de suas equipes, aproveitando assim o grande potencial terapêutico desses espaços.

\section{Referências}

ANVISA (2001). Resolução da diretoria colegiada $n^{\circ} 101$. São Paulo: ANVISA/SENAD.
Associação Brasileira de Amor-Exigente (2005). O que é Amor-Exigente. Retirado em 25/09/2005 de http://www.amorexigente.org.br

Bardin, L. (1977). Análise de conteúdo. Lisboa: Edições 70.

Bauman, Z. (2001). Modernidade líquida. Rio de Janeiro: Jorge Zahar Editora.

Bauman, Z. (2005). Identidade. Rio de Janeiro: Jorge Zahar Editora.

Birman, J. (1999). Mal estar na atualidade: A psicanálise e as novas formas de subjetivação. Rio de Janeiro: Civilização Brasileira.

Conte. M. (2003). A clínica psicanalítica com toxicômanos: O “corte \& costura" no enquadre institucional. Santa Cruz: EDUNISC.

Cruz, W. F. O. (2003). Intoxicação e exclusão social. Revista da Associação Psicanalítica de Porto Alegre, 13(24), 19-39.

Dalmolin, B. M., Lopes, S. M. B. \& Vasconcellos, M. P. C. (2002). A construção metodológica do campo: etnografia, criatividade e sensibilidade na investigação. Saúde e Sociedade, 11(2), 33-42. Retirado em 07/05/2007 em: http://apsp.org.br/saudesociedade/ XI_2/construcao_metodologica.htm.

De Leon, G. (2003). A comunidade terapêutica: teoria, modelo e método. São Paulo: Edições Loyola.

Dualib, C. (2006). Acolhimento para familiares de dependentes: um olhar sistêmico no trabalho com as famílias. Em D. X. Silveira \& F. G. Moreira (Orgs.), Panorama atual de drogas e dependências (pp. 261-265). São Paulo: Atheneu.

Federação Brasileira das Comunidades Terapêuticas (sd). Comunidades terapêuticas filiadas - titulares e provisórias. Retirado em 30/10/2006 em http://www.febract.org.br/filiadas.htm

Governo do Estado do Rio Grande do Sul (2001). Guia comentado para a implantação da portaria 16/01. Porto Alegre: Secretaria da Saúde.

Guimarães, J. L, Godinho, P. H, Cruz, R., Kappann, J, \& Tosta Junior, L. A. (2004). Consumo de drogas psicoativas por adolescentes escolares de Assis, SP. Revista de Saúde Pública, 38(1), 130-132.

Kaminer, Y. \& Szobot, C. (2004). O Tratamento de adolescentes com transtornos por uso de substâncias psicoativas. Em L. Pinsky \& M.A. Bessa (Orgs.), Adolescência e drogas (p. 164-178). São Paulo: Editora Contexto.

Levisky, D. L. (1997). Aspectos do processo de identificação do adolescente na sociedade contemporânea e suas relações com a violência. Em D.L. Levisky (Org.), Adolescência e violência: conseqüências da realidade brasileira (pp. 17-31). Porto Alegre: Artes Médicas.

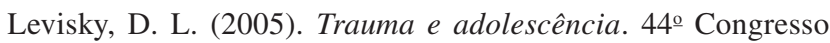
Internacional de Psicanálise. Rio de Janeiro: IPA.

Loss, M. \& Milnitsky-Sapiro, C. (2005). Processos psíquicos do engravidamento na adolescencia em contextos de periferia: impasses e possibilidades. Revista de Psicologia da USP, 16(4), 69-99.

Marlatt, G. A. \& Gordon, J. R. (1993). Prevenção de recaída: estratégias de manutenção no tratamento de comportamentos adictivos. Porto Alegre: Artes Médicas.

Melman, C. (1995). Haveria uma questão particular do pai na adolescência? Adolescência: revista da associação psicanalítica de Porto Alegre, 5(11), 11-26.

Menegaz, C. V. \& Milnitsky-Sapiro, C. (2002). Capricho ou oráculo: representações na imprensa sobre adolescentes. Revista de Ciências Humanas da UFSC, 6, 161-174.

Milnitsky-Sapiro, C. (2001) Uma metodologia para a formação de um profissional da área da saúde comprometido com a realidade social [Resumo]. Em IV Seminário de metodologia de projetos de extensão, Anais da $4^{\mathrm{a}}$ Jornada Científica. São Carlos: SEMPE. 
Oliveira, C. S. (2001). Sobrevivendo no inferno: a violência juvenil na contemporaneidade. Porto Alegre: Sulina.

Pillon, S. C; Luíz, M. A. V. (2004). Modelos explicativos para o uso de álcool e drogas e a prática de enfermagem. Revista Latinoamericana de Enfermagem, 12(4), 72-76.

Pratta, E. M. \& Santos, M. A. (2007). Lazer e uso de substâncias psicoativas na adolescência: possíveis relações. Psicologia: Teoria e Pesquisa, 23(1), 43-52.

Rassial, J. J. (1997). A passagem adolescente: da família ao laço conjugal. Porto Alegre: Artes e Ofícios.

Raupp, L. (2006). Adolescência, Drogadição e Políticas Públicas: Recortes no Contemporâneo. Dissertação de Mestrado, Universidade Federal do Rio Grande do Sul, Porto Alegre.

Raupp, L. \& Milnitsky-Sapiro, C. (2005). Reflexões sobre concepções e práticas contemporâneas das políticas públicas para adolescentes: o caso da drogadição. Saúde e Sociedade, 14(2), 60-68.

Rotelli, F. (1990). Onde está o senhor? Revista SaúdeLoucura, 3, $77-91$.
Sabino, N. D. M. \& Cazenave, S. O. (2005). Comunidades terapêuticas como forma de tratamento para a dependência de substâncias psicoativas. Revista Estudos de Psicologia (Campinas), 22(2), 167-174.

Serrat, S. M. (2002). Comunidades terapêuticas: mecanismo eficiente no tratamento de dependentes químicos. Retirado em 01/05/2004 de http://www. comciencia.br

Simões, M. P. (2006). Adolescência e uso de drogas. Em D. X. Silveira \& F. G. Moreira (Orgs.), Panorama atual de drogas e dependências (pp. 281-288). São Paulo: Atheneu.

Toscano, A. (2001). Adolescência e drogas. Em S. D. Seibel \& A. Toscano (Orgs.), Dependência de drogas (pp. 283-302). São Paulo: Editora Atheneu.

Recebido em 21.09.2006

Primeira decisão editorial em 19.07.2007

Versão final em 28.08.2007

Aceito em 08.12.2008 